\title{
HUBUNGAN KEDISIPLINAN MURID DAN PEMBERIAN TUGAS RUMAH \\ TERHADAP PRESTASI BELAJAR IPA KELAS IV SD NEGERI 100 \\ SALOKARAJA KECAMATAN MAIWA \\ KABUPATEN ENREKANG
}

\author{
Supardi Paturisi, Khaeruddin, Hilmi Hambali \\ Pendidikan Guru Sekolah Dasar, Fakultas Keguruan dan Ilmu Pendidikan, \\ Universitas Muhammadiyah Makassar \\ Iqramsyar34@gmail.com
}

\begin{abstract}
ABSTRAK
Tujuan penelitian ini adalah untuk mengetahui signifikansi hubungan antara : (1) Kedisiplinan Belajar Murid dengan Prestasi Belajar IPA kelas IV SDN 100 Salokaraja Kec. Maiwa Kab. Enrekang. (2) Pemberian Tugas Rumah dengan Prestasi Belajar IPA kelas IV SDN 100 Salokaraja Kec. Maiwa Kab. Enrekang. Penelitian ini menggunakan metode kuantitatif deskriptif. Populasi dari penelitian ini adalah seluruh murid kelas IV SDN 100 Salokaraja Kec. Maiwa Kab. Enrekang sejumlah 16 murid. Sedangkan sampel dalam penelitian ini adalah sampel populatif artinya semua individu di dalam populasi langsung dijadikan obyek penelitian. Teknik pengumpulan data menggunakan angket untuk memperoleh data tentang kedisiplinan belajar murid dan pemberian tugas rumah. Sedangkan dokumentasi digunakan untuk memperoleh data tentang prestasi belajar IPA kelas IV SDN 100 Salokaraja Kec. Maiwa Kab. Enrekang. Teknik analisis data menggunakan nonparametrik dengan menggunakan rumus korelasi tata jenjang dari Spearman.Berdasarkan hasil dari penelitian dapat disimpulkan : (1) Ada hubungan positif antara kedisiplinan belajar murid dengan prestasi belajar IPA murid kelas IV SDN 100 Salokaraja Kec. Maiwa Kab. Enrekang Tahun Ajaran 2016/2017 karena $r_{S}=0.64779>r_{0.05}(16)=0.497$. (2) Ada hubungan yang positif antara pemberian tugas rumah dengan prestasi belajar IPA murid kelas IV SDN 100 Salokaraja Kec. Maiwa Kab. Enrekang Tahun Ajaran 2016/2017 karena $r_{S}==0.607353>r 0.05(16)=0.49$
\end{abstract}

Kata Kunci : Kedisiplinan Murid; Pemberian Tugas Rumah; Prestasi Belajar IPA Kelas IV 


\section{PENDAHULUAN}

Dalam kehidupan suatu bangsa pendidikan mempunyai peranan yang sangat penting untuk menjamin perkembangan kelangsungankehidupan bangsa yang bersangkutan. Setiap individu mempunyai hak yang sama untuk mendapatkan pendidikan. Pendidikan dapat berlangsung pada lingkungan keluarga, lingkungan sekolah, dan lingkungan masyarakat.

Kemajuan pengetahuan pada era sekarang ini terasa semakin pesat dan cepat. Upaya mewujudkan pembangunan nasional bidang pendidikan diperlukan peningkatan dan penyelenggaraan pendidikan nasional yang disesuaikan dengan perkembangan ilmu pengetahuan dan teknologi, pengembangan masyarakat dan kebutuhan pembangunan.

Peningkatan mutu pendidikan perlu dilakukan secara menyeluruh meliputi aspek pengetahuan, keterampilan, sikap, dan nilai-nilai. Pada proses pembelajaran guru harus memperhatikan perkembangan. Sikap dari peserta didiknya, guru harus berusaha agar anak didiknya tidak lupa akan kewajibannya sebagai seorang murid baik di rumah maupun disekolah. Dengan diberikannya sebuah tugas rumah secara tidak langsung menyuruh peserta didik untuk membuka buku pelajaran di rumah dan sedikit banyak akan membaca materi pembelajaran minimal materi yang ada dalam tugas rumah tersebut.

Seorang anak yang disiplin dalam mengerjakan tugas secara tidak langsung dapat dipastikan bahwa anak tersebut belajar di rumah, dan anak yang tidak pernah mengerjakan tugas rumah secara tidak langsung dapat dikatakan bahwa anak tersebut tidak belajar di rumah, meskipun demikian terkadang ada anak yang mengerjakan tugas tersebut di sekolah yaitu sebelum pulang atau saat pagi pagi sebelum pelajaran dimulai,untuk itu unsur - unsur dalam sikap kedisiplinan haruslah mulai ditanamkan sejak dini..

Berdasarkan uraian di atas rumusan masalah dalam penelitian ini adalah: (1) Apakah ada hubungan antara kedisiplinan dengan prestasi belajar IPA? (2) Apakah ada hubungan antara pemberian tugas rumah dengan prestasi belajar IPA ?. Tujuan penelitian ini adalah: (1) Untuk mengetahui hubungan antara kedisiplinan dengan prestasi belajar IPA pada murid kelas IV SD Negeri 100 Salokaraja Kecamatan Maiwa Kabupaten Enrekang. (2) Untuk mengetahui hubungan antara pemberian tugas rumah 
dengan prestasi belajar IPA pada murid kelas IV SD Negeri 100 Salokaraja Kecamatan Maiwa Kabupaten Enrekang.

\section{Pengertian Prestasi Belajar}

Menurut Saiful Bahari Dhamarah Prestasi adalah hasil dari suatu kegiatan yang telah dikerjakan, atau diciptakan secara individu maupun secara kelompok sedangkan, R. Setiawan dan Conny berpendapat bahwa Hasil belajar atau preastasi belajar adalah suatu hasil yang telah dicapai oleh murid setelah melakukan kegiatan belajar.

Dalam pendapat yang lain juga di jelaskan oleh Prestasi adalah hasil yang telah dicapai seseorang dalam melakukan kegiatan. Gagne (1985:40) menyatakan bahwa prestasi belajar dibedakan menjadi lima aspek, yaitu : kemampuan intelektual, strategi kognitif, informasi verbal, sikap dan keterampilan. Menurut Bloom dalam Suharsimi Arikunto (1990:110) bahwa hasil belajar dibedakan menjadi tiga aspek yaitu kognitif, afektif dan psikomotorik.

Prestasi merupakan kecakapan atau hasil kongkrit yang dapat dicapai pada saat atau periode tertentu. Berdasarkan pendapat tersebut, prestasi dalam penelitian ini adalah hasil yang telah dicapai murid dalam proses pembelajaran. Jadi prestasi belajar adalah suatu hasil atau kemampuan maksimal seseorang dalam menguasai materi yang dipelajari dalam kegiatan belajar.

\section{Pengertian Tugas Rumah}

Pemberian tugas rumah berarti belajar sendiri dan berlatih hingga sampai siap sebagaimana mestinya pemberian tugas dimaksudkan yaitu guru menyajikan bahan pelajaran dengan cara memberikan tugas kepada murid, untuk dikerjakan dengan penuh rasa tanggung jawab dan kesadaran. Dalam pelaksanaannya bukan saja

hanya dilakukan oleh murid di rumah, akan tetapi pemberian tugas dapat dikerjakan / dilaksanakan di sekolah / halaman sekolah, perpustakaan, di masjid, di dan lain tempat.Tergantung jenis tugas yang diberikan. Setiap tugas-tugas murid harus ada. Dalam pelaksanaannya Pemberian tugas rumah ini diberikan kepada para murid pada akhir pelajaran, pokok bahasan atau sub pokok bahasan, bahkan pertemuan. Tugas yang diberikan hendaknya dipersiapkan dengan baik oleh guru sehingga dapat melahirkan penguasaan atas pengetahuan dan keterampilan tertentu.

Guru hendaknya membimbing pekerjaan tersebut, terutama bila para murid mengalami kesulitan serta memberikan petunjuk penyelesaiannya. Pemeriksaan terhadap PR tadi bisa dilakukan beberapa menit sebelum pelajaran dimulai pada jam 
bahasan berikutnya atau guru menyediakan waktu ekstra untuk itu. Ketika para murid tidak mengerjakan tugas, atau tugasnya belum selesai, bisa diberikan hukuman yang bersifat edukatif demi mendorong motivasi mereka.

\section{Indikator Kedisiplinan}

Menurut Arikunto (1990:137) dalam penelitian mengenai kedisiplnannya membagi tiga macam indikator kedisiplinan, yaitu: 1) perilaku kedisiplinan di dalam kelas, 2) perilaku kedisiplinan di luar kelas di lingkungan sekolah, dan 3) perilaku kedisiplinan di rumah. Tu'u (2004:91) dalam penelitian mengenai disiplin sekolah mengemukakan bahwa indikator yang menunjukan pergeseran / perubahan hasil belajar murid sebagai kontribusi mengikuti dan menaati peraturan sekolah adalah dapat mengatur waktu belajar di rumah, rajin dan teratur belajar, perhatian yang baik saat belajar di kelas, dan ketertiban diri saat belajar di kelas.

Sedangkan menurut Syafrudin (2005:80) membagi indikator disiplin belajar menjadi empat macam, yaitu: 1) ketaatan terhadap waktu belajar, 2) ketaatan terhadap tugas-tugas pelajaran, 3) ketaatan terhadap penggunaan fasilitas belajar, dan 4) ketaatan menggunakan waktu datang dan pulang. Berdasarkan apa yang telah di kemukakan oleh Arikunto dan Syarifudin, maka dalam penelitian ini membagi indikator disiplin belajar menjadi empat macam, yaitu:

a. Ketaatan terhadap tata tertib sekolah

b. Ketaatan terhadap kegiatan belajar di sekolah

c. Ketaaatan dalam mengerjakan tugas-tugas pelajaran

d. Ketaatan terhadap kegiatan belajar di rumah

Dalam kehidupan sehari-hari telah terdapat keyakinan bahwa anak memerlukan sedikit disiplin agar ia dapat bertingkah laku sesuai dengan standar norma masyarakat dan agar ia dapat diterima dalam lingkungan masyarakat.

\section{Pembelajaran IPA Di Sekolah Dasar}

Mengenai hakikat IPA, S. Kastanto, dkk (2009: 1) mengungkapkan bahwa ilmu pengetahuam yang berkaitan erat dengan cara mencari tahu tentang alam secara sistemati. IPA bukan hanya penguasaan kumpulan pengetahuan yang berupa faktafakta, konsep-konsep, atau prinsip-prinsip saja, tetapi juga merupakan suatu proses penemuan.

Dalam Kurikulum Sekolah Pendidikan Guru Ilmu Pendidikan Alam didefinisikan sebagai Pengetahuan yang tersusun teratur dan terumuskan mengenai gejala-gejala 
materi, yang terutama didasarka atas pengamatan, eksperimen dan induksi, termasuk cara memperluas pengetahuan itu serta kriteria pengujian kebenarannya.

Dari uraian di atas dapat disimpulkan Ilmu Pengetahuan Alam (IPA) merupakan ilmu pengetahuam yang berkaitan erat dengan cara mencari tahu tentang alam secara tersusun teratur dan terumuskan mengenai gejala-gejala materi, yang terutama didasarkan atas pengamatan, eksperimen dan induksi, termasuk cara memperluas pengetahuan itu serta kriteria pengujian kebenarannya.

\section{METODE PENELITIAN}

Jenis Penelitian ini menggunakan pendekatan kuantitatif dengan jenis penelitian pra eksperimental (Pre-Experimental) yakni penelitian yang belum merupakan eksperimen sungguhan karena tidak adanya variabel kontrol yang digunakan dalam penelitian.

Populasi dalam penelitian ini adalah semua murid kelas IV Sekolah Dasar Negeri 100 Salokaraja tahun pelajaran 2016/2017 sebanyak 16 siswa. dalam penelitian ini, sampling tidak dipergunakan karena semua populasi dijadikan subyek penelitian (total sampling). Dalam penelitian ini peneliti menggunakan teknik statistik karena data yang peneliti ambil merupakan data kuantitatif. Sedangkan analisis yang digunakan adalah analisis korelasi ganda suatu korelasi yang bermaksud untuk melihat hubungan antara tiga atau lebih variabel (dua atau lebih variabel independent dan satu variabel dependent).

\section{HASIL PENELITIAN DAN PEMBAHASAN}

\section{Deskripsi Data}

Dalam penelitian ini terdapat dua variabel bebas, yaitu variabel kedisiplinan murid (X1) dan variabel pemberian tugas rumah $\left(\mathrm{X}_{2}\right)$. Sedangkan variabel prestasi belajar IPA (Y) sebagai variabel terikat.

Melalui proses pengumpulan data melalui metode yang telah ditentukan yaitu metode angket dan metode dokumentasi diperoleh deskripsi data sebagai berikut:

\section{a. Deskripsi Data Kedisiplinan Murid (X1)}

Data hasil pengamatan untuk variabel kedesiplinan belajar murid dapat dideskripsikan sebagai berikut : 
Tabel 1 Distribusi Frekuensi skor kedisiplinan belajar murid.

\begin{tabular}{|c|c|c|c|c|c|c|c|}
\hline Interval & Bb & $\mathbf{X}_{\mathbf{i}}$ & f & Fkum & $\mathbf{X}_{\mathbf{i}}{ }^{2}$ & $f_{x i}$ & $\mathbf{F}_{\mathbf{i}}{ }^{2}$ \\
\hline $47-55$ & 46,5 & $\begin{array}{l}5 \\
1\end{array}$ & 7 & 7 & 2601 & 357 & 18207 \\
\hline $56-64$ & 55,5 & $\begin{array}{l}6 \\
0\end{array}$ & 0 & 7 & 3600 & 0 & 0 \\
\hline $65-73$ & 64,5 & $\begin{array}{l}6 \\
9\end{array}$ & 0 & 7 & 4761 & 0 & 0 \\
\hline $74-82$ & 73,5 & $\begin{array}{l}7 \\
8\end{array}$ & 8 & $\begin{array}{l}1 \\
5\end{array}$ & 6084 & 624 & 48672 \\
\hline $83-91$ & 82,5 & $\begin{array}{l}8 \\
7\end{array}$ & 1 & $\begin{array}{l}1 \\
6\end{array}$ & 7569 & 87 & 7569 \\
\hline Jumlah & & 345 & $\begin{array}{l}1 \\
6\end{array}$ & & $\begin{array}{l}2461 \\
5\end{array}$ & 1068 & 74448 \\
\hline
\end{tabular}

Distribusi frekuensi variabel kedisiplinan belajar murid diperoleh nilai - nilai statistik sebagai berikut :

a. Mean

$$
\bar{x}=\frac{\sum f_{1} x_{1}}{\sum f_{1}}=\frac{1068}{16}=66.75
$$

b. Modus

$$
M_{o}=b+p\left(\frac{b_{1}}{b_{1}+b_{2}}\right)=382.5+8\left(\frac{8-0}{(8-0)(8-1)}\right)=77.767
$$

c. Median

$$
M_{e}=b+p\left(\frac{\frac{1}{2} n-F}{f}\right)=73.5+8\left(\frac{\frac{1}{2} 16-7}{8}\right)=74.5
$$

d. Sandart Deviasi

$$
s=\sqrt{\frac{n \sum f_{1} x_{1}^{2}-\left(\sum f_{1} x_{1}\right)^{2}}{n(n-1)}}=\sqrt{\frac{16.74448-1068^{2}}{16(16-1)}}=66.75
$$


Distribusi data variabel kedisiplinan belajar murid dapat digambarkan dalam bentuk grafik berikut ini.

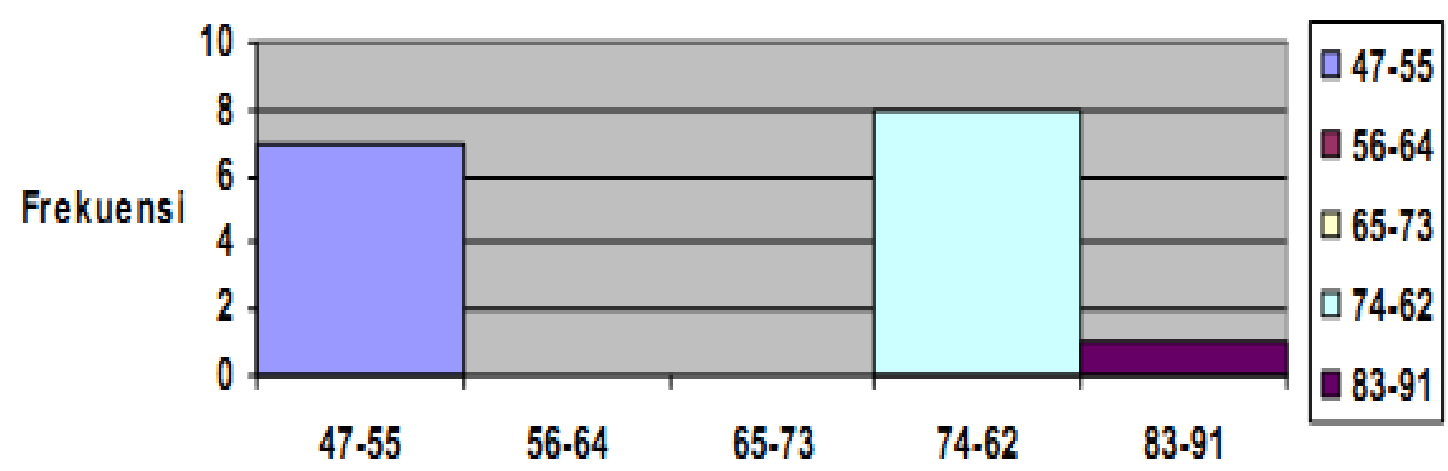

\section{Grafik Distribusi Frekuensi Kedisiplinan Murid}

\section{b. Deskripsi Data Variabel Pemberian Tugas Rumah (X2)}

Data dari variabel pemberian tugas rumah dapat dideskripsikan sebagai berikut:

Tabel 2 Distribusi Frekuensi skor pemberian tugas rumah

\begin{tabular}{|c|c|c|c|c|c|c|c|}
\hline Interva & $\mathbf{b b}$ & $\mathbf{X} \mathbf{i}$ & $\mathbf{F}$ & $\mathbf{F} \mathbf{k u m}$ & $\mathbf{X}_{\mathbf{i}}{ }^{\mathbf{2}}$ & $\mathbf{F x}$ & $\mathbf{F i}^{\mathbf{2}}$ \\
\hline $40-46$ & 39,5 & 43 & 7 & 7 & 1849 & 301 & 12943 \\
\hline $47-55$ & 46,5 & 51 & 0 & 7 & 2601 & 0 & 0 \\
\hline $56-64$ & 55,5 & 60 & 2 & 9 & 3600 & 120 & 7200 \\
\hline $65-73$ & 64,5 & 69 & 7 & 16 & 4761 & 483 & 33327 \\
\hline $74-82$ & 73,5 & 78 & 0 & 16 & 6084 & 0 & 0 \\
\hline Jumlah & & 301 & 16 & & 18895 & 904 & 53470 \\
\hline
\end{tabular}

Dari tabel distribusi frekuensi variabel pemberian tugas rumah diperoleh nilainilai statistik sebagai berikut :

a. Mean

$$
\bar{x}=\frac{\sum f_{1} x_{1}}{\sum f_{1}}=\frac{847}{16}=54.625
$$

b. Modus

$$
M_{o}=b+p\left(\frac{b_{1}}{b_{1}+b_{2}}\right)=36.5+6\left(\frac{7-0}{(7-0)(7-0)}\right)=39.5
$$


c. Median

$$
M_{e}=b+p\left(\frac{\frac{1}{2} n-F}{f}\right)=52.5+6\left(\frac{\frac{1}{2} 16-7}{2}\right)=55.5
$$

d. Standart Deviasi

$$
s=\sqrt{\frac{n \sum f_{1} x_{1}^{2}-\left(\sum f_{1} x_{1}\right)^{2}}{n(n-1)}}=\sqrt{\frac{16.50728-874^{2}}{16(16-1)}}=14.109
$$

Distribusi data variabel pemberian tugas rumah dapat digambarkan dalam bentuk grafik berikut ini :

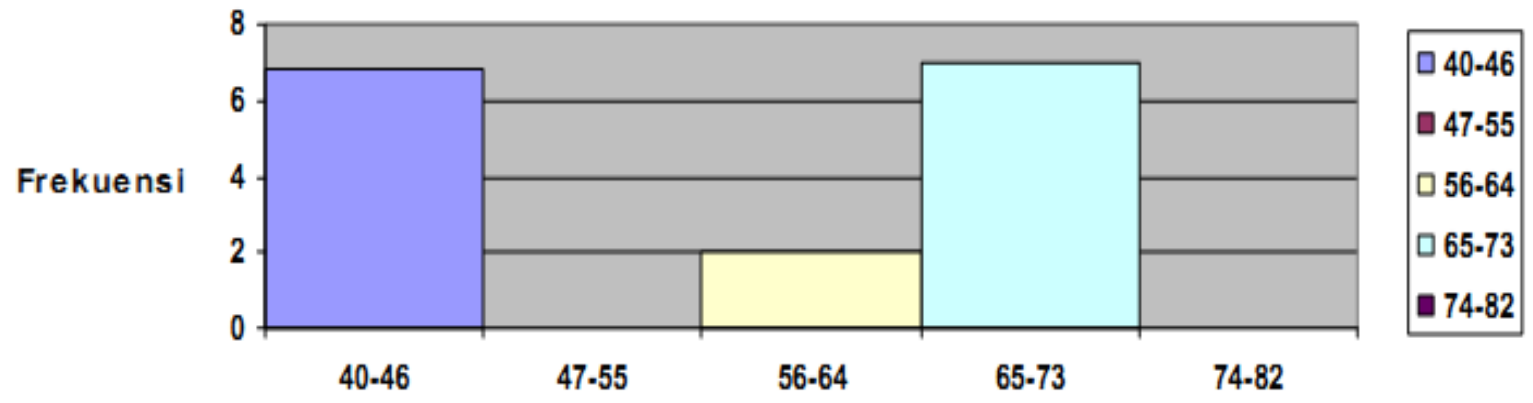

\section{Grafik Distribusi Frekuensi Pemberian Tugas Murid}

\section{c. Deskripsi Data Variabel Prestasi Belajar IPA (Y)}

Data dari variabel prestasi belajar IPA murid dapat di buat dalam bentuk distribusi frekuensi sebagai berikut :

Tabel 2 Distribusi Frekuensi Variabel Prestasi Belajar IPA (Y).

\begin{tabular}{|c|c|c|c|c|c|c|c|}
\hline Interva & $\mathbf{b b}$ & $\mathbf{X} \mathbf{i}$ & $\mathbf{F}$ & $\mathbf{F} \mathbf{k u m}$ & $\mathbf{X} \mathbf{i}$ & $\mathbf{f x i}$ & \\
\hline $1-2$ & 0.5 & 1.5 & 0 & 0 & 2.25 & 0 & 0 \\
\hline $3-4$ & 2.5 & 3.5 & 0 & 0 & 12.25 & 0 & 0 \\
\hline $5-6$ & 4.5 & 5.5 & 5 & 5 & 30.25 & 27.5 & 151.25 \\
\hline $7-8$ & 6.5 & 7.5 & 2 & 7 & 56.25 & 15 & 112.5 \\
\hline $9-10$ & 8.5 & 9.5 & 9 & 16 & 90.25 & 85.5 & 812.25 \\
\hline Jumlah & & 27.5 & 16 & & 191.25 & 128 & 1076 \\
\hline
\end{tabular}

Dari tabel distribusi frekuensi variabel prestasi belajar IPA murid diperoleh nilai-nilai statistik sebagai berikut :

a. Mean 


$$
\bar{x}=\frac{\sum f_{1} x_{1}}{\sum f_{1}}=\frac{128}{16}=8
$$

b. Modus

$$
M_{o}=b+p\left(\frac{b_{1}}{b_{1}+b_{2}}\right)=8.5+1\left(\frac{9-2}{(9-2)(9-0)}\right)=8.9375
$$

c. Median

$$
M_{e}=b+p\left(\frac{\frac{1}{2} n-F}{f}\right)=8.59+1\left(\frac{\frac{1}{2} 16-7}{9}\right)=8.611
$$

d. Standar Deviasi

$$
s=\sqrt{\frac{n \sum f_{1} x_{1}^{2}-\left(\sum f_{1} x_{1}\right)^{2}}{n(n-1)}}=\sqrt{\frac{16.1076-128^{2}}{16(16-1)}}=1.8619
$$

Distribusi data variabel prestasi belajar IPA murid dapat digambarkan dalam bentuk grafik berikut ini :

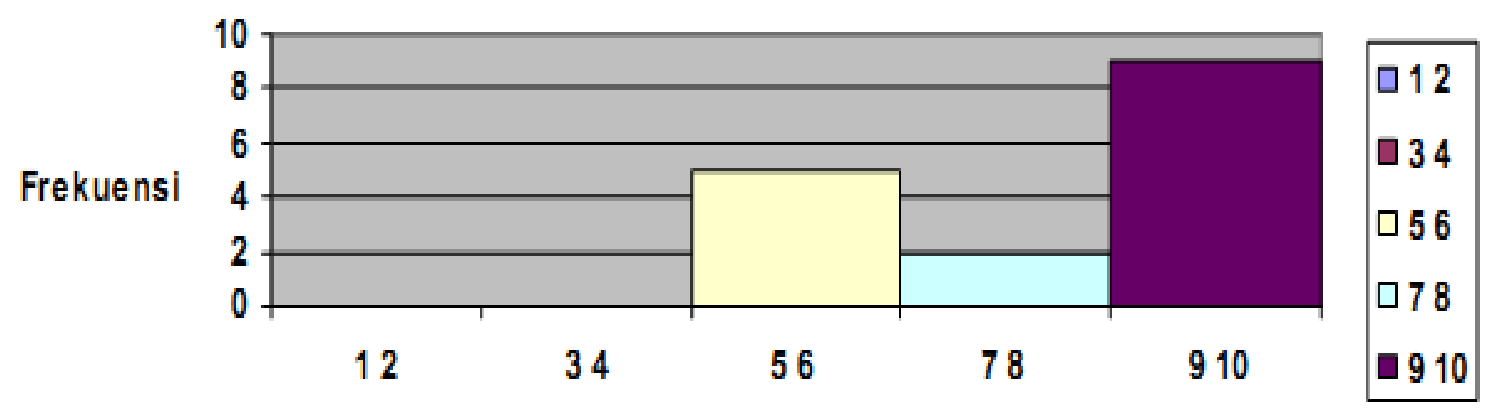

Grafik Distribusi Frekuensi Prestasi Belajar IPA

Keterangan :

Interval = Susunan data menerut kelas interval tertentu atau menurut kategori tertentu dalam sebuah data.

$\mathrm{BB}=$ Batas bawah dari nilai interval.

$\mathrm{Xi}=$ Nilai tegah dari pada interval.

$\mathrm{F} \quad=$ Frekuensi.

$\mathrm{F}$ kum = Frekuensi Kumulatif. 


\section{Uji Validitas dan Reliabilitas}

Dalam menganalisa data, maka perlu diadakan terlebih dahulu pengujian terhadap validitas dan reliabilitas data. Adapun uji validitas dengan menggunakan product moment, sedangkan untuk untuk menguji reliabilitas data menggunakan metode belah dua (split half). Berikut ini akan diuraikan uji validitas dan uji reliabilitas masing-masing variabel.

\section{Uji validitas masing-masing variabel bebas}

a. Uji validitas variabel kedisiplinan belajar murid (X1)

Dari hasil pengujian validitas item variabel kedisiplinan murid diperoleh item yang tidak valid adalah 18, 24 dan 26 sehingga item yang tidak valid tersebut dihilangkan dan jumlah item yang valid menjadi 27. Setelah item yang tidak valid tersebut dihilangkan, maka dilanjutkan dengan uji reliabilitas terhadap item yang valid.

b. Uji validitas variabel pemberian tugas rumah (X2)

Dari hasil pengujian validitas item variabel pemberian tugas rumah terdapat item yang tidak valid, yaitu 2, 6, 7, 8, 10, 24 dan 26, sehingga item yang tidak valid tersebut dihilangkan dan jumlah item yang valid menjadi 23. Untuk selanjutnya dapat dilakukan uji reliabilitas pada variabel kedisiplinan belajar murid dengan menguji item yang valid.

\section{Uji reliabilitas masing-masing variabel bebas}

a. Uji reliabilitas variabel kedisiplinan belajar murid (X1).

Pengujian reliabilitas variabel kedisiplinan belajar murid menggunakan split half (metode belah dua). Dengan metode tersebut dapat diperoleh nilai reiabilitas sebesar 0.903 yang lebih besar dari rtabel pada tingkat signifikansi $5 \%$ dengan $\mathrm{n}=16$, yaitu sebesar $0,497(\mathrm{r}=0.903>\mathrm{r}$ tabel $=0.497)$. Oleh karena itu angket pertanyaan tersebut reliabel.

b. Uji reliabilitas variabel kedisiplinan belajar murid (X2).

Pengujian reliabilitas variabel pemberian tugas rumah dilakukan dengan menggunakan metode split half (metode belah dua). Dengan metode tersebut diperoleh nilai reliabilitas sebesar 0,942 yang lebih besar dari rtabel pada tingkat signifikansi $5 \%$ dengan $\mathrm{n}=16$, yaitu sebesar 0,497 $(\mathrm{r}=0.942>\mathrm{r}$ tabel=0.497). Oleh karena itu angket pertanyaan tersebut reliabel. 


\section{Analisis Data}

Hipotesis yang akan diuji dalam penelitian ini adalah hubungan antara kedisiplinan murid dengan prestasi belajar IPA dan hubungan antara pemberian tugas rumah dangan prestasi belajar IPA. Secara statistik hipotesis tersebut dituliskan sebagai berikut :

1. $\mathrm{H}_{\mathrm{O}}$ : tidak ada hubungan (korelasi) kedisiplinan murid dengan prestasi belajar IPA murid kelas IV SD Negeri 100 Salokaraja Kecamatan Maiwa Kabupaten Enrekang.

$\mathrm{Ha}$ : ada hubungan (korelasi) kedisiplinan murid dengan prestasi belajar IPA murid kelas IV SD Negeri 100 Salokaraja Kecamatan Maiwa Kabupaten Enrekang.

2. $\mathrm{H}_{\mathrm{O}}$ : tidak ada hubungan (korelasi) pemberian tugas rumah dengan prestasi belajar IPA murid kelas IV SD Negeri 100 Salokaraja Kecamatan Maiwa Kabupaten Enrekang.

$\mathrm{Ha}_{\mathrm{a}}$ : ada hubungan (korelasi) pemberian tugas rumah dengan prestasi belajar IPA murid kelas IV SD Negeri 100 Salokaraja Kecamatan Maiwa Kabupaten Enrekang.

3. Dengan menggunakan tingkat signifikansi $5 \%$.

4. Perhitungan statistik.

Uji statistik yang digunakan adalah analisis korelasi ranking Spearman. Langkah-langkah yang perlu dilakukan dalam analisis korelasi ranking Spearman adalah sebagai berikut :

a. Masing-masing variabel independent (X) dan variabel dependen (Y) dirangking.

b. Apabila terdapat nilai pengamatan yang sama, rankingnya adalah rataratanya.

c. Menentukan selisih ranking $\left(d_{i}\right)$ untuk setiap pasang variabel X dan $Y$.

d. Menghitung nilai statistik $\mathrm{r}_{\mathrm{S}}$ dengan rumus :

$$
r_{s}=1-\left(\frac{6 \sum d_{1}^{2}}{N\left(n^{2}-1\right)}\right)
$$

Dengan daerah kritik, tolak $\mathrm{H}_{\mathrm{O}}$ bila $\mathrm{r}_{\mathrm{S}}>\mathrm{r}$ tabel $=\mathrm{r}_{\alpha}(\mathrm{n})$.

5. Pengambilan Kesimpulan

Keputusan dapat diambil dengan melihat hasil statistik hitung $r_{S}$ dan membandingkannya dengan $\mathrm{r}$ pada tabel dengan ketentuan sebagai berikut : 
a. Ho diterima jika $\mathrm{r}_{\mathrm{S}}$ lebih kecil dari r pada tabel.

b. $\mathrm{H}_{\mathrm{O}}$ ditolak jika $\mathrm{r}_{\mathrm{S}}$ lebih besar dari r pada tabel.

\section{Uji Hipotesis}

Setelah melalui tahap pengujian validitas dan reliabilitas data sehingga diperoleh data yang bernilai valid dan reliabel, maka dapat dilanjutkan uji hipotesa dengan menggunakan metode ranking spearman. Dalam penelitian ini, analisa data bertujuan untuk mengetahui hubungan antara kedisiplinan belajar murid dengan prestasi belajar IPA dan hubungan antara pemberian tugas rumah dengan prestasi belajar IPA. Berikut ini akan diuraikan analisis data masing-masing variabel bebas dengan variabel terikat tersebut.

1. Hubungan antar variabel kedisiplinan belajar murid $\left(\mathrm{X}_{1}\right)$ dengan variabel prestasi belajar IPA (Y).

a. Hipotesis

$\mathrm{H}_{\mathrm{O}}$ : tidak ada hubungan (korelasi) kedisiplinan belajar murid dengan prestasi belajar IPA.

$\mathrm{H}_{\mathrm{a}}$ : ada hubungan (korelasi) kedisiplinan belajar murid dengan prestasi belajar IPA.

b. Menggunakan taraf signifikansi $\alpha=5 \%$.

c. Dengan menggunakan uji statistik :

$$
r_{s}=1-\left(\frac{6 \sum d_{1}^{2}}{N\left(n^{2}-1\right)}\right)
$$

Dengan daerah kritik, tolak HO jika $r_{S}>$ tabel $=r_{0.05}(16)=0.49$.

d. Kesimpulan

$$
\text { Karena } r_{S}=0.64779>r_{0.05(16)}=0.497 \text {, maka } \mathrm{H}_{\mathrm{O}} \text { ditolak. Hal }
$$

ini berarti terdapat hubungan kedisiplinan murid dengan prestasi belajar IPA. Karena $\mathrm{r}_{\mathrm{S}}$ mempunyai nilai yang positif, maka kedisiplinan belajar siswa dengan prestasi belajar IPA murid memiliki hubungan yang positif.

2. Hubungan antara variabel pemberian tugas rumah $\left(\mathrm{X}_{2}\right)$ dengan variabel prestasi belajar IPA (Y).

\section{a. Hipotesis}

$\mathrm{H}_{\mathrm{O}}$ : tidak ada hubungan (korelasi) pemberian tugas rumah dengan prestasi belajar IPA. 
$\mathrm{H}_{\mathrm{a}}$ : ada hubungan (korelasi) pemberian tugas rumah dengan prestasi belajar IPA.

b. Menggunakan taraf signifikansi $\alpha=5 \%$.

c. Dengan menggunakan uji statistik :

$$
r_{s}=1-\left(\frac{6 \sum d_{1}^{2}}{N\left(n^{2}-1\right)}\right)
$$

Dengan daerah kritik, tolak $\mathrm{H}_{\mathrm{OS}}$ jika $\mathrm{r}_{\mathrm{S}}>\mathrm{r}$ tabel $=\mathrm{r} 0.05(16)=0.497$.

d. Kesimpulan

Karena $r_{S}=0.607353>r_{0.05}(16)=0.497$, maka $\mathrm{H}_{\mathrm{O}}$ ditolak dan $\mathrm{H}_{\mathrm{a}}$ diterima. Hal ini berarti terdapat hubungan pemberian tugas rumah dengan prestasi belajar IPA murid. Karena $\mathrm{r}_{\mathrm{S}}$ mempunyai nilai yang positif, maka antara pemberian tugas rumah dengan prestasi belajar IPA murid memiliki hubungan yang positif.

Dari hasil penelitian sebelum dan sesudah diterapkan kedisiplinan dan pemeberian tugas rumah kepada murid di ketahui bahwa terjadi peningkatan prestasi belajar IPA murid dengan materi gerak benda dapat di pengarui oleh bentuk dan ukuran. Hasil ini ini dapat dilihat pada pengujian hipotesisnya.

Berdasarkan analisis prestasi belajar IPA murid yang dijadikan sampel penelitian sebelum dan sesudah diberikan perlakuan, murid yang berada pada kategori sangat rendah setelah diberikan perlakuan lebih sedikit dibandingkan dari kategori sangat rendah sebelum diberikan perlakuan. Hal ini disebabkan dengan pengetahuan murid terhadap materi yang diajarkan yaitu kedisiplinan dan pemberian tugas rumah.

Pada data atau kolom Frekuensi prestasi belajar IPA jumlah murid yang tuntas ada 11 orang dari jumlah murid 16 dan dapat dilihat pada grafik distribusi frekuensi prestasi belajar IPA digrafik itu menunjukkan peningkatan prestasi belajar IPA yang sangat siknifikan ini menunjukkan adanya keberhasilan dalam proses pembelajaran yakni dengan penerapan kedisiplinan murid dan pemberian tugas rumah. Perlu kita ketahui bahwa cara belajar yang baik bukanlah bakat sejak lahir, cara belajar adalah sesuatu kemampuan yang dapat dimiliki oleh setiap murid dengan jalan latihan. Melalui kedisiplinan inilah latihan dibiasakan. Kemanpuan itu harus digunakan secara terus menerus sehingga menjadi kebiasaan yang melekat pada dirinya dan akhirnya menjadi kebiasaan yang melekat pada dirinya dan akhirnya unsur keteraturan dan kedisiplinan 
tidak akan terasa sebagai beban yang berat.

Dengan pemberian tugas rumah diharapkan menumbuhkan proses pembelajaran yang eksploratif, mendorong prilaku kreatif dan memupuk kemandirian dalam proses pembelajaran murid.

\section{SIMPULAN DAN SARAN}

Berdasarkan analisis dan pembahasan hasil penelitian dengan merujuk pada rumusan masalah, maka dapat diambil kesimpulan sebagai berikut : (1) Ada hubungan yang positif kedisiplinan belajar murid dengan prestasi belajar IPA siswa kelas IV SD Negeri 100 Salokaraja Kecamatan Maiwa Kabupaten Enrekang. Hal ini ditunjukkan oleh nilai korelasi $r$ yang positif yaitu $r_{S}=0.64779>r$ tabel=0.497. Artinya semakin baik kedisiplinan belajar murid akan semakin meningkatkan prestasi belajar IPA murid. (2) Ada hubungan yang positif pemberian tugas rumah dengan prestasi belajar IPA murid kelas IV SD Negeri 100 Salokaraja Kecamatan Maiwa Kabupaten Enrekang. Hal ini ditunjukkan oleh nilai korelasi $r$ yang positif yaitu $\mathrm{r}_{\mathrm{S}}=0.607353$ $>\mathrm{r}$ tabel $=0.497$. Artinya semakin sering guru memberikan pekerjaan rumah maka anak akan senantiasa belajar di luar lingkungan sekolah ini akan membuat prestasi belajar ipa semakin meningkat.

Berdasarkan hasil penelitian dan kenyataan yang ada di lapangan maka penulis memberikan saran-saran sebagai berikut :

1. Untuk murid

a. Hendaknya setiap siswa meningkatkan intensitas belajar pada setiap matapelajaran yang diperoleh untuk meningkatkan kedisiplinan pribadi.

b. Siswa hendaknya melaksanakan tugas-tugas yang diberikan dalam upaya meningkatkan kesadaran diri untuk belajar tanpa tekanan dan paksaan.

2. Untuk guru

Guru hendaknya memahami pentingnya kedisiplinan dan pemberian tugas rumah dalam usaha meningkatkan prestasi belajar khususnya mata pelajaran eksakta seperti ilmu pengetahuan alam dan matematika yang selama ini ditakuti murid dengan memberikan banyak latihan soal-soal

3. Untuk masayarakat

Hendaknya masyarakat dapat memperbaiki kondisi lingkungannya dengan menciptakan suasana yang nyaman bagi anak-anak untuk belajar 
serta menenamkan kedisiplinan dengan membuat wajib jam belajar.

4. Untuk peneliti lanjut

Para peneliti terutama tentang kedisiplinan dan pemberian tugas rumah dapat menggunakan penelitian-penelitian yang sudah ada sebagai bahan acuan untuk penelitian-penelitian selanjutnya dengan memperhatikan faktor-faktor lain yang lebih luas dan terkait dalam rangka peningkatan prestasi belajar murid.

\section{DAFTAR PUSTAKA}

Abdul Majid. 2007. Perencanaan Pembelajaran. Bandung: PT. Remaja Rosdakarya.

http://alhafizh84wordpress.com/2011/10/16/metode-pemberian-tugas-//) tanggal 18 Maret 2016.

http://goresantintapemimpi.blogspot.co.id/2012/06/instrumen-untukmengungkaptingkat.html

https://nurdinkhan.wordpress.com/2012/05/30/angket-kedisiplinan-murid/

Kerlinger, Fred N. 2006. Asas-asas Penelitian Behavioral. Yogyakarta : Gadjah Mada University Press.

Kurikulum 2004 Untuk Sekolah Dasar. 2003. Jakarta : Departemen Pendidikan Nasional.

Kurnia Inggridwati dkk. 2008. Perkembangan Belajar Peserta Didik. Jakarta: Departemen Pendidikan Nasional.

Lie Anita. 2010. Cooperative Learning. Jakarta : PT.Gramedia Widia sarana Indonesia.

Nasin Elkabumaini dan Rahmat Ruhyana 2016. Panduan Implementasi Pendidikan Budi Pekerti. Margahayu permai, Bandung.

Mulyani Sumantri dan Johar Permana. 2002. Strategi Belajar Mengajar. Bandung.

Prof. Dr. Sugiyono. 2011. Metode Penelitian Kuantitatif, Kualitatif dan R \& D. Ikapi Bandung

Padmono. 1999. Evaluasi Pengajaran Untuk Program D 2 PGSD. Kebumen .

Suparno, Paul dkk. 2002. Pendidikan Budi Pekerti di Sekolah : Suatu Tinjauan Umum. Yogyakarta : Kanisius

Sutrisno Hadi. 1995. Metodologi Risearch I, Yogyakarta, UGM Press. 1989. Statistik, Yogyakarta, Andi Ofset. 
Soerdjono Soekamto. 1998. Disiplin Menuju Sukses, Jakarta, Ghalia.

Suprijono Agus.2009. Cooperative Learning.Surabaya :Pustaka Belajar

Undang-Undang Dasar Republik Indonesia Tahun 1945. Tentang Pembukaan. 